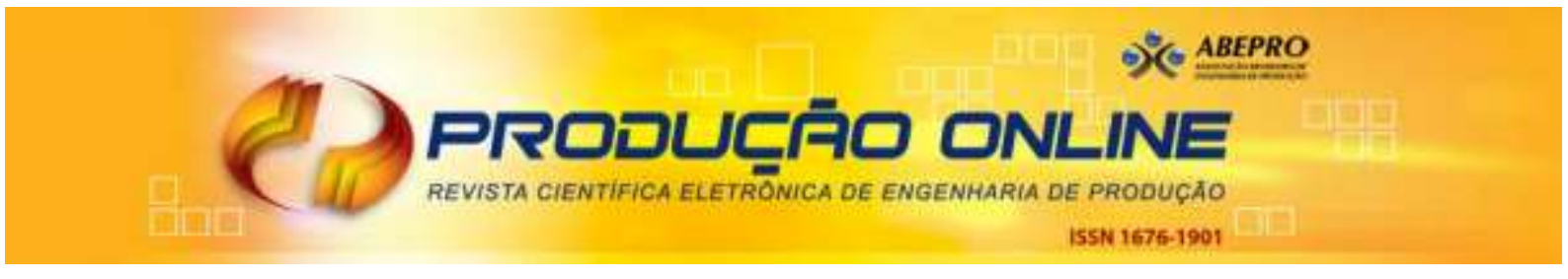

\title{
APRENDIZAGEM ATIVA NO ENSINO DE ENGENHARIA DE MÉTODOS: UMA EXPERIÊNCIA NO CEFET/RJ
}

\section{ACTIVE LEARNING IN TEACHING OF ENGINEERING METHODS: AN EXPERIENCE AT CEFET/RJ}

\author{
Karina Fernandes Brum* E-mail: karina brum@yahoo.com.br \\ Paula Michelle Purcidonio* E-mail: paulamichelle 4@hotmail.com \\ Marta Lucia Azevedo Ferreira* E-mail: marta.ferreira57@gmail.com \\ ${ }^{*}$ Cefet/RJ, Rio de Janeiro, RJ
}

Resumo: Este artigo tem por objetivo descrever e avaliar a experiência de aprendizagem ativa realizada na disciplina Engenharia de Métodos do curso de Engenharia de Produção do Centro Federal de Educação Tecnológica Celso Suckow da Fonseca (Cefet/RJ). A dinâmica de grupo foi a estratégia adotada para o desenvolvimento de um método melhorado utilizando o tabuleiro e os pinos do jogo "Resta Um". Trata-se de uma pesquisa de natureza aplicada com finalidade descritiva baseada em dados bibliográficos e na observação ativa, direta e sistemática da experiência com apoio de um questionário contendo perguntas abertas e fechadas. Ela foi realizada em duas turmas durante 0 ano de 2015 com a participação de 57 alunos. A dinâmica combinou aspectos típicos dos jogos, simulações e da aprendizagem baseada em equipes. Ela foi considerada por eles plenamente satisfatória, tanto em termos da motivação gerada, como da sua importância para a disciplina e o curso, tendo sido sugerida a sua continuidade nas próximas turmas. A utilização de estratégias de aprendizagem ativa favorece o desenvolvimento de competências em sentido amplo que é, sem dúvida, o requisito por excelência do mercado de trabalho nos dias de hoje.

Palavras-chave: Aprendizagem Ativa. Dinâmica de Grupo. Engenharia de Produção. Engenharia de Métodos. Cefet/RJ.

Abstract: This paper aims to describe and evaluate the active learning experience carried out in the discipline "Engineering Methods" of the Production Engineering Course at the Federal Centre for Technological Education Celso Suckow da Fonseca (Cefet/RJ). Group dynamics was the adopted strategy to develop a better method, using the board and pegs of the game "Peg Solitaire". It is an applied research with descriptive goal, based on bibliographic data and on active, direct and systematic observation of the experience, with the help of a questionnaire, which included both open and closed questions. The research was conducted with two classes during the year of 2015, involving 57 participating students. The dynamics combined typical aspects of the games, the simulations and aspects of team-based learning. It was considered to be fully satisfactory by the students, both in terms of generated motivation and in terms of its importance for the discipline and the course, suggesting its future implementation with other classes. The use of active learning strategies favors the development of skills under a wide perspective, which is, without any doubt, the most common and important pre-requisite of the job market nowadays.

Keywords: Active Learning. Group Dynamics. Production Engineering. Engineering Methods. Cefet/RJ. 


\section{INTRODUÇÃO}

As universidades em todo o mundo vêm enfrentando o desafio de adaptação às novas exigências de formação profissional que requerem também novas maneiras de ensinar e de aprender. O seu papel é cada vez mais importante para os países, pois o crescimento e o desenvolvimento econômico se apoiam na competitividade, que é fortemente dependente da qualificação de mão de obra. Os engenheiros de produção desempenham papel fundamental nesses processos ao participarem ativamente das atividades de Pesquisa, Desenvolvimento e Inovação (P,D\&l) e da melhoria contínua de produtos e processos.

A necessidade de levar em conta sistemas humanos e sociais aumenta significativamente a complexidade dos problemas da engenharia de produção em comparação com as outras engenharias, favorecendo a utilização de estratégias de aprendizagem ativa no processo formativo (IAROZINSKI NETO \& LEITE, 2010). Mais do que técnicas, métodos ou metodologias, tais estratégias visam promover um ambiente que permita aos alunos "aprender a aprender" por meio da aquisição simultânea de conhecimentos, habilidades, atitudes e valores (DUARTE, 2001; FERREIRA \& SILVA, 2016; ZAMBELO, 2011).

Segundo a Associação Brasileira de Engenharia de Produção (Abepro), a engenharia de produção se divide em dez áreas dentre as quais a engenharia de operações e processos de produção que engloba a engenharia de métodos. Esta subárea envolve o estudo de tempos e movimentos, ou seja, o estudo sistemático de sistemas de trabalho visando o desenvolvimento de métodos, a sua padronização, bem como a determinação de tempos-padrão e do treinamento de trabalhadores nos novos métodos (BARNES, 1977).

Assim, este artigo se propõe a descrever e avaliar a experiência de aprendizagem ativa realizada durante 0 ano de 2015 na disciplina Engenharia de Métodos do curso de Engenharia de Produção do Centro Federal de Educação Tecnológica Celso Suckow da Fonseca (Cefet/RJ). Depois dessa breve introdução, apresenta-se nas seções dois e três a revisão da literatura sobre esses temas, na seção quatro a metodologia adotada e na seção cinco a experiência mencionada. $\mathrm{Na}$ sequência são apresentadas as considerações finais e referências utilizadas. 


\section{APRENDIZAGEM ATIVA E ENSINO DE ENGENHARIA DE PRODUÇÃO}

A aprendizagem ativa é um conceito amplo, na medida em que inclui qualquer método de ensino capaz de promover o engajamento dos alunos no processo de aprendizagem (PRINCE, 2004). Ela deve ser significativa para eles, ou seja, deve levá-los a raciocinar sobre o que estão fazendo, estimulando a reflexividade. Em geral as atividades ocorrem na sala de aula e são planejadas de modo que os estudantes se sintam motivados a processar, aplicar, interagir e compartilhar experiências, contrapondo-se às tradicionais aulas expositivas que promovem a aprendizagem passiva.

Embora a aprendizagem colaborativa englobe a aprendizagem cooperativa, o autor considera que a primeira privilegia as interações em contraposição ao trabalho individual, enquanto a última busca incentivar a cooperação em detrimento da competição. Porém, nos dois casos, os alunos trabalham em pequenos grupos visando alcançar objetivos e metas comuns, o que traz muitos benefícios para a sua aprendizagem. As atividades colaborativas auxiliam a retenção de conteúdos, melhoram o desempenho dos estudantes e promovem atitudes positivas e aquelas de natureza cooperativa estimulam as habilidades interpessoais e 0 desenvolvimento de equipes, reforçando-se mutuamente.

$\mathrm{O}$ autor aponta a aprendizagem baseada em problemas (problem-based learning) como um importante mecanismo para incentivar atitudes positivas nos alunos ao buscarem a solução de problemas reais e complexos. A aprendizagem orientada a projetos (project-oriented learning) desenvolve habilidades de comunicação oral e escrita por meio de apresentações e relatórios, enquanto a aprendizagem por descoberta (discovering learning) é estimulada através de questões, observações e problemas a serem investigados em profundidade pelos alunos.

A aprendizagem ativa pode ser obtida também pela introdução de questões a serem respondidas em aula (inquiry learning), pelo ensino baseado no estudo de caso (case-based teaching) visando a análise de situações, problemas e a tomada de decisões e pelo ensino na hora certa (just-in-time teaching) com o objetivo de interligar atividades realizadas em classe e atividades extra-classe (PRINCE \& FELDER, 2006). 
A aprendizagem baseada em equipes (team based learning), por sua vez, é utilizada na discussão de situações-problema por diferentes grupos na mesma sala de aula com vistas ao aproveitando dos conhecimentos e experiências prévios dos alunos, de modo a tornar a aprendizagem mais significativa para eles e promover o desenvolvimento de equipes. Os problemas são tratados a partir do diálogo que estimula a reflexão e a crítica em relação a situações, problemas, práticas e processos comuns em determinada atividade profissional.

Os conceitos são abordados pelos professores antes da realização das atividades e o estudo preliminar por parte dos alunos é recomendado. Apesar das discussões e trocas de experiências durante a realização dos trabalhos em sala de aula, as equipes devem buscar o consenso, compartilhando com as demais os resultados alcançados, o que serve de base para o debate conduzido pelo professor com a turma a partir das relações entre teoria e prática. A responsabilidade individual e coletiva dos alunos e a parceria com o professor - que atua mais propriamente como consultor ou facilitador - constituem importantes elementos motivadores (MICHAELSEN \& SWEET, 2008; PARMELEE \& MICHAELSEN, 2010).

Vale acrescentar os jogos $\mathrm{e}$ as simulações que oferecem aos alunos oportunidades de ensaio e erro e de enfrentamento de desafios. Eles propiciam a vivência de situações reais em condições de baixo risco e estimulam o "aprender fazendo", enquanto as dinâmicas de grupo auxiliam a expansão do potencial individual e grupal ao incentivarem a criatividade e a sociabilidade (SILVA et al., 2016; ZAMBELO, 2011). A competição está presente nos jogos, ainda que os jogos cooperativos enfatizem o componente lúdico estimulando o bom humor, a alegria, a espontaneidade e a imaginação, tornando a aprendizagem mais agradável e gratificante (GRAMIGNA, 2007; SOLER, 2003).

A aprendizagem baseada em problemas, projetos e equipes tem um amplo espectro de aplicações no ensino de engenharia de produção. A reflexão sobre a ação é tão importante quanto a emoção e o sentimento relacionado à ação. A atitude positiva, o bom humor e a alegria facilitam a aprendizagem e por isso devem ser valorizados. Estas atividades são naturalmente participativas e promovem o maior engajamento dos alunos. Ao aplicarem conhecimentos em situações práticas, eles aprendem a se expressar melhor e com mais autoconfiança, melhorando o processo decisório e o relacionamento com professores e colegas. A formação e preparação 
dos grupos, por sua vez, é fundamental para que eles se tornem equipes de alto desempenho.

Os jogos que permitem simulações de processos produtivos também são particularmente úteis, como mostram Depexe et al. (2006) a partir da utilização do lego system. As dinâmicas de grupo aplicadas por Possebon et al. (2012) em três casos de trabalho-padrão auxiliaram a apropriação de conceitos e a resolução de problemas. Os autores ressaltam que o entusiasmo entre os alunos é comum, na medida em que eles aprendem de maneira interativa e divertida. A competição entre os membros dos grupos e entre os grupos existe, mas a solidariedade também está presente, resultando em uma atividade motivadora e que ainda contribui para a criatividade e a desinibição dos estudantes.

Os jogos remontam aos primórdios da história e possuem regras que determinam o que vale no mundo por eles circunscrito. Eles têm caráter especial e excepcional por serem livres, representando a evasão da vida real para uma esfera temporária de atividade com orientação própria. O divertimento proporcionado e o seu caráter desinteressado se aliam ao fascínio que exercem sobre os alunos. Embora cativantes, eles instauram a tensão da incerteza e do acaso e a busca da solução motivada pelo desejo de ganhar e pelo esforço para levá-los até o final (GRAMIGNA, 2007; HUIZINGA, 2000).

Militão e Militão (1999) acrescentam em relação às dinâmicas de grupo que elas podem ser usadas em vários momentos dos cursos e situações nas salas de aula ou aplicadas para amenizar o tratamento de temas difíceis, delicados ou simplesmente para descontrair os alunos. Como afirma Gramigna (2007), diferentemente do ensino diretivo teórico ou prático tradicional centrado nos professores, o ensino participativo busca, em diferentes graus, o maior envolvimento dos alunos nas decisões ao tornar as aulas mais atraentes para eles, ampliando suas possibilidades de engajamento.

Independentemente da nomenclatura adotada, a aprendizagem ativa pode ser estimulada por intermédio de atividades múltiplas e combinadas. As atividades colaborativas e cooperativas são complementares no sentido de promoverem atitudes e comportamentos positivos, constituindo importantes mecanismos de intervenção pedagógica (PRINCE, 2004; PRINCE \& FELDER, 2006). Com efeito, a 
compreensão e a descoberta de fenômenos e suas relações com conhecimentos prévios constituem importantes dimensões da formação profissional.

Trata-se de proporcionar aos estudantes materiais conceituais e empíricos que serão úteis para o seu exercício profissional futuro. Os professores passam a atuar como orientadores, supervisores e facilitadores do processo de aprendizagem, contribuindo mais pela sua experiência do que por sua autoridade, ainda que esta seja mantida. Enfim, alunos e professores se tornam parceiros (BAZZO, 2011; FERREIRA \& SILVA, 2016). Entretanto, esta parceria é um desafio a ser vencido no ensino de engenharia de produção, marcado pela baixa contextualização de conteúdos e predominância de aulas expositivas que estimulam a aprendizagem passiva dos alunos (CARMO et al., 2010).

\section{ESTUDO DE TEMPOS E MOVIMENTOS E ENGENHARIA DE MÉTODOS}

Desde o surgimento no século XIX, o estudo de tempos e movimentos registrou diversas contribuições, como a de Frederick Taylor (1856-1915) com o estudo de tempos - que foi usado principalmente para determinação do tempopadrão para atividades específicas do ambiente produtivo - e os trabalhos de Frank Gilbreth (1868-1924) e sua esposa Lilian Gilbreth (1878-1972) com o estudo de movimentos - que foi empregado na melhoria de métodos de trabalho (BARNES, 1977).

Para o autor, os principais fundamentos da engenharia de métodos se baseiam nesses dois estudos que vêm tendo influência fundamental na melhoria de métodos operacionais e de condições de trabalho, permitindo análises do processo produtivo, das atividades, da relação homem-máquina e das operações em geral. $\mathrm{O}$ objetivo básico do estudo de tempos e movimentos é definir o tempo necessário para a realização de uma determinada atividade por método racional e executada em cadência normal por uma pessoa qualificada e habituada a determinada técnica.

Assim, o desenvolvimento de um método para a fabricação de um novo produto ou a melhoria de um método existente é um dos objetivos fundamentais da engenharia de métodos. A metodologia empregada no planejamento do projeto de método decorre de uma forma criativa de resolução de problemas que é baseada em um modo lógico e sistemático de procurar a solução de qualquer problema denominada processo geral de problema-solução (BARNES, 1977). 
Como afirmam Vieira et al. (2015), para a implantação de métodos melhores e mais fáceis de executar uma tarefa, é preciso que eles sejam estudados todos os detalhes relativos ao trabalho em busca de informações particulares com uma análise de cada um dos passos sobre determinada operação no processo. 0 trabalho deve ser analisado de maneira sistemática e os métodos devem ser práticos e eficientes, ou seja, devem visar a padronização de processos e a efetividade na utilização de recursos.

Nessa perspectiva, Barnes (1977) sugere quatro enfoques a serem considerados no desenvolvimento de possíveis soluções, a partir das quais se deve selecionar o método preferido: eliminar todo trabalho desnecessário; combinar operações ou elementos; modificar a sequência das operações; e simplificar as operações essenciais. Estes quatro enfoques constituem a base a partir da qual devem ser propostas as melhorias no método estudado.

O primeiro enfoque parte do pressuposto de que grande parte das tarefas que são executadas normalmente não é realmente necessária. Em muitas situações, o trabalho ou processo não deveria ser submetido à simplificação ou melhoria, mas ser inteiramente eliminado. Tal enfoque pode ser exemplificado com a eliminação da câmara de ar de pneus de um automóvel que, através do desenvolvimento de uma roda e um pneu que pudesse prender o ar, permitiu que fosse eliminada a utilização da câmara.

O segundo enfoque considera a necessidade de combinar operações ou elementos. Muitas vezes, a divisão de um processo em uma grande quantidade de operações pode causar manuseio excessivo de materiais, ferramentas e equipamentos. Assim, em determinadas situações, é possível tornar o trabalho mais simples pela combinação de duas ou mais operações ou alterações no método que permitam a combinação de operações.

Normalmente, o início da produção de um novo produto é feito em pequenos lotes de fabricação experimentais. Com aumentos graduais, a produção poderá se tornar bastante significativa, mas a sequência original de operações poderá ser a mesma que aquela empregada no início. Por esse motivo, o terceiro enfoque aborda a necessidade de questionar a ordem na qual as várias operações são executadas.

A simplificação das operações essenciais é o quarto enfoque proposto por Barnes (1977), ou seja, após o estudo do processo produtivo e a execução de todas 
as melhorias que se apresentam como promissoras, o próximo passo consiste na análise de cada operação acompanhada da tentativa de simplificá-la ou melhorá-la.

A partir do bom senso e da experiência, Fullmann (2009) afirma que os princípios de economia de movimentos são um excelente ponto de partida para a simplificação do trabalho, sendo mais econômicos do que qualquer outro estudo e mais rentáveis do que qualquer aquisição de novo equipamento. Os funcionários, tanto nas oficinas, como nos escritórios, melhoram a eficiência e diminuem a fadiga, o que traz mais resultado com menos esforço. Estes princípios são assim descritos:

Quadro - Princípios de Economia de Movimentos

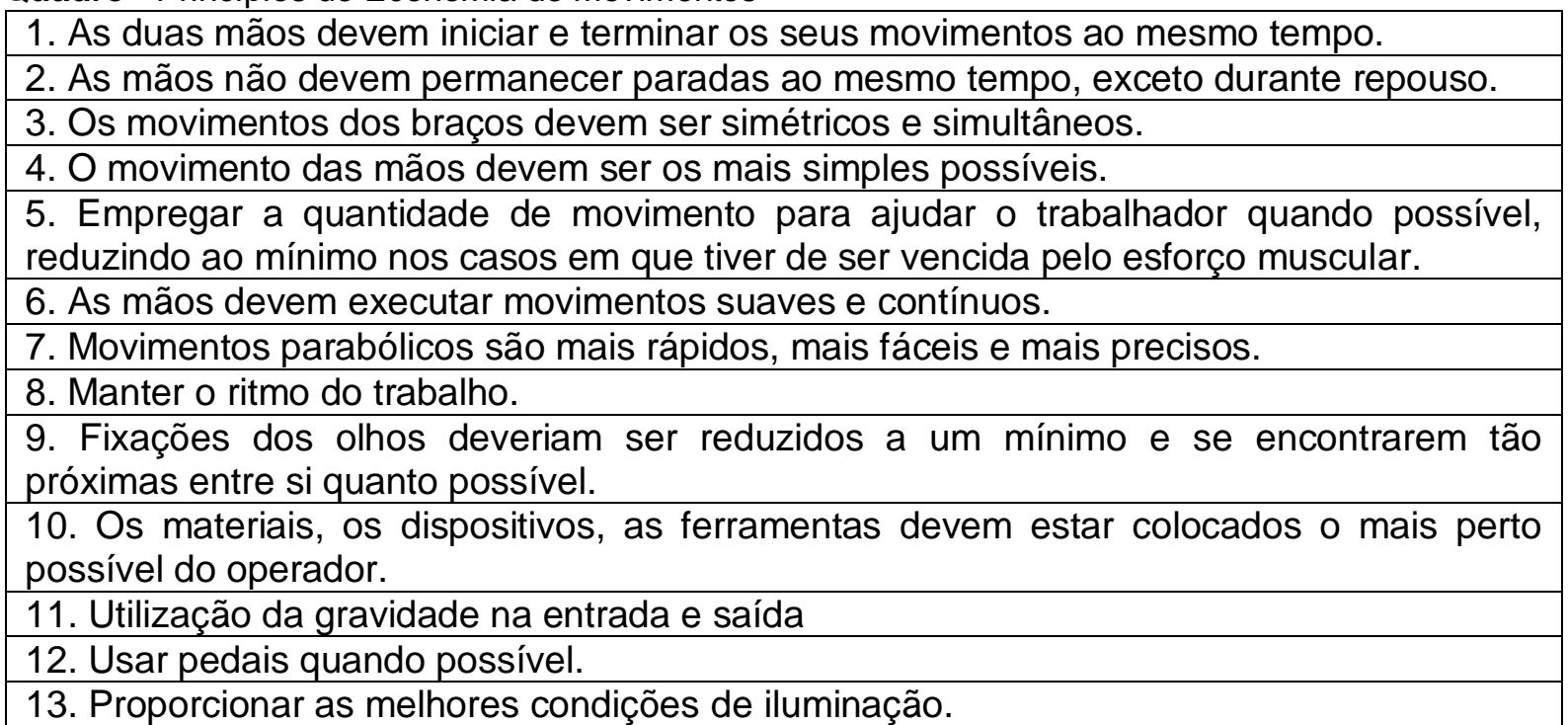
Fonte: Adaptado pelas autoras de Barnes (1977)

Segundo Peinado e Graeml (2007), a aplicação dos princípios de economia de movimentos permite o aumento da produtividade na execução de tarefas em qualquer tipo de organização. Juntamente com os quatro enfoques mencionados, tais princípios representam um importante instrumento na elaboração de um estudo de movimentos para reduzir o número de atividades e movimentos na execução de diversas tarefas, como se pretende mostrar nas seções seguintes.

\section{METODOLOGIA}

Este artigo é baseado em uma pesquisa aplicada e descritiva, voltando-se mais para a utilização dos conhecimentos do que para o desenvolvimento de teorias e ao mesmo tempo apresentando as características de um determinado grupo e situação (GIL, 2011). A experiência de aprendizagem ativa relatada a seguir foi 
realizada na disciplina Engenharia de Métodos do curso de Engenharia de Produção do Cefet/RJ ao longo de 2015, ou seja, contemplou uma turma em cada semestre, perfazendo o total de 57 alunos (BRUM \& PURCIDONIO, 2016). A estratégia selecionada foi a dinâmica de grupo combinando aspectos típicos dos jogos, simulações e da aprendizagem baseada em equipes.

Vale dizer que as técnicas de pesquisa incluem, tanto o conjunto de preceitos da pesquisa, como a habilidade para usá-los na obtenção de seus propósitos, caracterizando a parte prática da coleta de dados. Assim, foram utilizadas técnicas baseadas em material já elaborado como a pesquisa bibliográfica e em fatos percebidos diretamente como a observação ativa e sistemática da experiência complementada pela aplicação de um questionário com perguntas abertas e fechadas ao final da mesma em cada turma. Desse modo, as autoras tiveram rápido acesso a informações e esclarecimentos necessários ao acompanhamento dos observados (GIL, 2011).

\section{APRENDIZAGEM ATIVA NO ENSINO DE ENGENHARIA DE MÉTODOS: UMA EXPERIÊNCIA NO CEFET/RJ}

Embora a vocação profissionalizante do Cefet/RJ tenha sido definida em 1917, ele passou a oferecer cursos de engenharia a partir dos anos 70 em resposta às demandas do setor produtivo. Em 1992 surgiu o Programa de Pós-Graduação em Tecnologia (PPTEC) - atualmente denominado Programa de Pós-Graduação em Produção e Sistemas (PPPRO) - e em 1998 surgiu o curso de graduação em Engenharia de Produção. O Departamento de Engenharia de Produção (Depro) foi criado em 1999 para conferir identidade e dar suporte ao novo curso em razão da alta demanda, que o transformou naquele com a maior relação de candidatos por vaga, as maiores médias de aprovação no vestibular do Cefet/RJ e o maior número de alunos inscritos (FERREIRA et al., 2014).

Como afirmam os autores, o curso busca oferecer aos alunos, tanto a sólida base de conhecimentos que é própria da engenharia e comum a todos os engenheiros, independentemente da modalidade, como aquela que é própria da engenharia de produção, de modo que os egressos sejam capazes de conceber, projetar, implementar, manter e aperfeiçoar sistemas produtivos de naturezas diversas. O curso pretende ainda desenvolver nos alunos habilidades como 
criatividade, capacidade de resolução de problemas, consciência crítica, raciocínio lógico e capacidade de liderança e de expressão oral, gráfica e escrita. Em relação às atitudes e valores, a proposta é fortalecer a ética e a consciência de responsabilidade social.

A disciplina Engenharia de Métodos tem como objetivo desenvolver a capacidade de analisar as interações entre produtividade, mão de obra e maquinário, a fim de identificar "gargalos" em sistemas produtivos e propor melhorias. Trata-se de uma disciplina de natureza aplicada oferecida no terceiro período letivo do curso juntamente com as disciplinas Equações Diferenciais Ordinárias, Cálculo Vetorial, Cálculo Numérico, Mecânica Geral, Eletricidade Básica e Estatística. Vale ressaltar as interfaces existentes com as disciplinas Ergonomia, Custos Industrias e Planejamento e Controle da Produção I. A seguir são descritas as instruções da experiência de aprendizagem ativa selecionada, bem como as características da sua aplicação e a avaliação levando em conta as opiniões e percepções dos alunos.

\subsection{Instruções}

A dinâmica de grupo teve início com a escolha aleatória pela professora de cinco alunos que tiveram a responsabilidade de observar os demais grupos. O objetivo deste grupo de controle foi validar os métodos desenvolvidos pelos outros grupos. Cada observador recebeu um roteiro com as orientações necessárias e as informações que deveriam ser registradas quanto à atuação de cada grupo juntamente com os princípios de economia de movimentos que deveriam ser considerados pelos grupos. Os observadores foram orientados a não interferir na definição dos métodos, registrando apenas o desempenho de cada grupo.

Os demais alunos participantes formaram cinco grupos que foram orientados a se reunir em uma mesa. Em seguida, cada grupo recebeu um kit com os seguintes elementos: um roteiro com orientações gerais; um roteiro com todas as informações que deveriam ser registradas pelo grupo; um tabuleiro, seis pinos pretos, doze vermelhos e seis azuis e um recipiente que deveria ser usado para colocar todos os pinos na primeira execução do método de montagem do tabuleiro.

O objetivo da dinâmica de grupo foi apresentado logo no início da aula, de modo que os alunos tivessem tempo de entender a atividade e esclarecer dúvidas. 
Tratava-se de desenvolver um método melhorado para montagem do tabuleiro com os pinos do jogo "Resta Um" a partir de determinadas funções e responsáveis identificados. Cada grupo deveria definir o gerente, os controladores de qualidade e os operadores.

Os alunos deveriam indicar o número de pessoas que iria desempenhar cada uma das funções, o que naturalmente resultou em variações. Houve grupos que definiram uma pessoa, enquanto outros estabeleceram duas e até mesmo três pessoas em cada função. A identificação dos responsáveis ficou a cargo dos grupos, mas o preenchimento da folha de controle foi uma tarefa atribuída ao gerente.

As instruções foram as seguintes: cada grupo deveria estabelecer as responsabilidades de cada componente (gerência, controle de qualidade e operadores), definir o layout e os recursos necessários (onde ficariam os pinos, como eles estariam dispostos, quantos operários seriam utilizados), estabelecer um método melhorado contendo sua descrição e o seu tempo de execução, além de um quadro resumo, comparando o método padrão com o método melhorado.

O primeiro método executado deveria ser feito obrigatoriamente por dois operadores segurando apenas um pino em cada mão, sendo estes todos misturados e alocados no recipiente contido no kit, mas sem a utilização de acessórios ou de ferramentas que pudessem auxiliá-los e sempre seguindo a disposição previamente definida, conforme a figura exibida na página seguinte.

Os grupos deveriam cronometrar o tempo de execução do método. Depois da execução conforme o método proposto, eles poderiam propor as melhorias fazendo quantas tentativas achassem necessárias até alcançarem o método melhorado. $A$ única exigência feita aos grupos foi quanto à disposição dos pinos no tabuleiro, que deveria corresponder ao modelo apresentado, como mostra a figura. 
Figura - Modelo para Montagem do Tabuleiro e Disposição dos Pinos

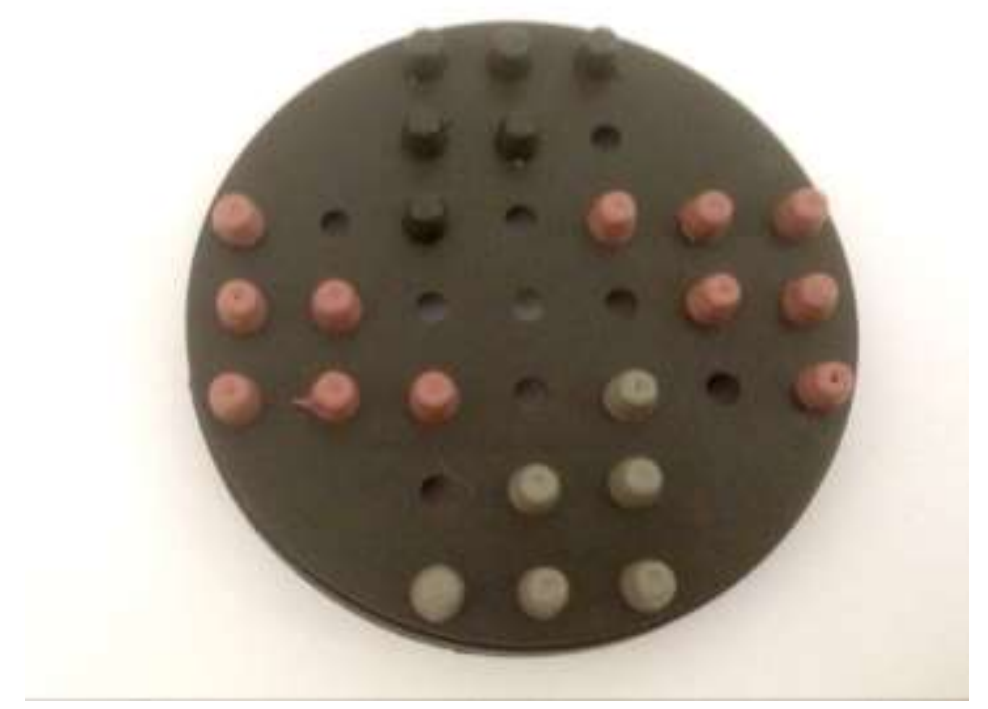

Fonte: Brum e Purcidonio (2016)

Após as diversas tentativas de diferentes métodos, cada grupo atingiu um método que acreditava ser o ideal. Foi solicitado aos grupos também que a cada mudança de método fosse brevemente anotado porque determinado método não agradou ou o que os levou a tentar de uma nova maneira. O método melhorado precisaria ser descrito detalhadamente e comparado ao primeiro método apresentado, além de conter os comentários e as conclusões que embasaram a escolha do método preferido.

\subsection{Aplicação}

O objetivo da estratégia de aprendizagem ativa selecionada foi proporcionar aos alunos a aplicação dos conceitos da disciplina por meio de uma vivência prática visando o desenvolvimento de equipes. A proposta foi levá-los a desenvolver um método melhorado através da aplicação dos quatro enfoques propostos por Barnes (1997) e dos princípios de economia de movimentos sugeridos pelo autor. Os conhecimentos necessários à realização da dinâmica foram ministrados por meio de aulas expositivas e, deste modo, o tabuleiro e os pinos do jogo "Resta Um" foram posteriormente usados visando o melhor entendimento dos conceitos apresentados.

Após a distribuição dos kits aos grupos, eles foram instruídos a iniciar a dinâmica a partir das orientações descritas no roteiro recebido. Depois da leitura das orientações, os grupos definiram as responsabilidades de cada componente e o 
gerente registrou as informações na folha apropriada. Em seguida, todos analisaram como executar o método de montagem definido no roteiro que deveria ser executado por dois operadores, segurando apenas um pino em cada mão, estes todos misturados dentro de em pequeno recipiente e seguindo a disposição dos pinos no tabuleiro indicada no modelo apresentado previamente.

Depois da execução do método proposto, cada grupo fez de quatro a dez tentativas. Cada uma delas possuía algum diferencial que eles achavam que poderia ajudar na eliminação de movimentos e permitisse maior rapidez na execução, além de buscarem sempre acrescentar os enfoques e princípios propostos por Barnes (1977). A cada tentativa os grupos observavam algo que achavam que poderia ser diferente e passível de melhoramento e então faziam um novo experimento até atingirem o método melhorado e preferido.

Alguns grupos adicionaram suportes para fixar o tabuleiro na mesa $e$ separaram os pinos por cor, outros optaram por delegar a responsabilidade de montagem para as alunas por executarem com mais facilidade e rapidez. Surgiram diversas ideias boas e interessantes. Após a definição do melhor método, cada grupo apresentou os resultados encontrados, argumentando sobre as escolhas feitas e os obstáculos encontrados no decorrer do seu desenvolvimento. Depois, os observadores de cada grupo foram convidados para a validação do método desenvolvido pelos grupos e a verificação da devida aplicação dos enfoques e princípios de economia de movimentos, indicando ainda eventuais violações.

\subsection{Avaliação}

Após as apresentações dos grupos e debates sobre os resultados práticos alcançados, os alunos foram levados a avaliar a dinâmica respondendo a um questionário com perguntas fechadas e também abertas, de modo que pudessem expressar livremente suas opiniões e percepções. Eles deveriam indicar o grau de concordância em relação a itens selecionadas e posteriormente descrever sua perspectiva sobre a dinâmica realizada por intermédio de comentários, críticas e sugestões. A Tabela a seguir sintetiza a avalição dos 57 alunos que participaram da experiência de aprendizagem ativa na disciplina Engenharia de Métodos em 2015. 
Tabela - Avaliação dos Alunos das Turmas 2015.1 e 2015.2 sobre a Dinâmica de Grupo

\begin{tabular}{|l|c|c|c|c|c|c|}
\hline $\begin{array}{l}\text { Tópicos } \\
\text { /Grau de concordância }\end{array}$ & $\begin{array}{c}\text { Concordo } \\
\text { Plenamente }\end{array}$ & Concordo & $\begin{array}{c}\text { Concordo } \\
\text { Parcialmente }\end{array}$ & Discordo & $\begin{array}{c}\text { Discordo } \\
\text { Plenamente }\end{array}$ & $(5)+(4)$ \\
\hline & $5(\%)$ & $4(\%)$ & $3(\%)$ & $2(\%)$ & $1(\%)$ & $\%$ \\
\hline Aprendizagem & $57,9 \%$ & $36,8 \%$ & $5,2 \%$ & & & $94,7 \%$ \\
\hline Motivação & $89,5 \%$ & $10,5 \%$ & & & & $100,0 \%$ \\
\hline Percepção da prática & $51,8 \%$ & $37,5 \%$ & $10,7 \%$ & & & $89,3 \%$ \\
\hline Continuidade & $78,6 \%$ & $21,4 \%$ & & & & $100,0 \%$ \\
\hline Importância & $64,9 \%$ & $36,9 \%$ & & & & $100,0 \%$ \\
\hline
\end{tabular}

Fonte: Brum e Purcidonio (2016)

Observando as respostas obtidas, verifica-se que os tópicos com melhor avaliação foram motivação e continuidade. Em mais de $75 \%$ dos casos, os alunos concordaram plenamente com a afirmação de que a dinâmica facilitou o entendimento dos conteúdos ministrados, devendo ser aplicada em outras turmas e disciplinas do curso. Eles relataram que aulas mais dinâmicas são mais interessantes e facilitam a assimilação de conhecimentos e se mostraram bastante envolvidos, além de terem expressado o desejo de novas aulas baseadas em dinâmicas de grupo. De fato, alunos motivados e interessados, rendem muito mais do que alunos que se mostram indiferentes aos conteúdos ministrados.

O tópico importância também foi muito bem avaliado, o que pode ser explicado a partir da observação de que os alunos reagiram de maneiras diferentes e novas aos temas abordados. Isto ocorreu porque eles tiveram a oportunidade de constatar que tudo aquilo que Ihes foi ensinado teve uma função importante e uma aplicação. Os conceitos de abstratos se tornaram reais, "fazendo mais sentido para eles" e sendo absorvidos de forma mais agradável e fácil. As dinâmicas de grupo favorecem a descontração, auxiliando a expansão do potencial individual e grupal e ao mesmo tempo a criatividade, a sociabilidade e o desenvolvimento de equipes (MILITÃO \& MILITÃO, 1999; SILVA et al., 2016; ZAMBELO, 2011).

Vale destacar que em todos os itens indicados para avaliação, o percentual de aceitação foi maior do que 85\% (soma dos graus de concordância 5 e 4), o que é um indicador de que a utilização de estratégias inovadoras agrega valor a uma aula ou a um conteúdo e que os alunos realmente apreciaram a dinâmica de grupo proposta. Vale ressaltar também que os itens motivação, continuidade e importância foram extremamente bem avaliados (concordância plena em 100\% dos casos). Entende-se que o objetivo foi alcançado com a realização da dinâmica de grupo e que os alunos 
gostariam de um maior número de oportunidades de aprendizagem ativa nos cursos de engenharia de produção, contrariando a constatação de Carmo et al. (2010). A motivação é maior nas atividades participativas, aumentando o engajamento dos alunos e tornando a aprendizagem mais fácil, satisfatória e completa.

Dentre os comentários registrados nos questionários, destacam-se os seguintes: estimular os alunos a "se interessarem" e aprenderem; tornar as aulas menos cansativas, possibilitando maior integração com os colegas; facilitar a consolidação de conhecimentos unindo teoria e prática; contribuir para a melhor formação profissional; motivar o trabalho em equipe; encontrar maneiras de ampliar as experiências na universidade; "sair" de metodologias tradicionais que em geral desmotivam os alunos; buscar metodologias mais dinâmicas e ricas em vertentes como liderança, proatividade e pensamento lógico; e valorizar a importância da disciplina Engenharia de Métodos no curso de Engenharia de Produção.

De modo geral, a dinâmica foi muito proveitosa e bem avaliada na opinião dos alunos das duas turmas. Eles demonstraram animação, interesse e vontade de dar continuidade à experiência em razão da facilidade de assimilação dos conteúdos teóricos ministrados nas aulas expositivas. Verificou-se que as estratégias de aprendizagem ativa atraem a atenção dos alunos e possibilitam o desenvolvimento de habilidades, atitudes e valores exigidos pelo mercado de trabalho ampliando, assim, o conceito de competência para além do domínio de conhecimentos específicos. Verificou-se ainda que a dinâmica de grupo é uma estratégia pedagógica fácil de ser aplicada, somando-se a experiências de mesma natureza realizadas em outras disciplinas do curso de Engenharia de Produção do Cefet/RJ (FERREIRA \& SOUZA, 2011; FERREIRA et al., 2014).

\section{CONSIDERAÇÕES FINAIS}

A união do método tradicional de ensino com diversos tipos de dinâmica de ensino-aprendizagem é fundamental para a formação integral dos estudantes. A graduação em engenharia de produção oferece uma espécie de "caixa de ferramentas" que vai se completando com cada disciplina concluída. Porém, a dificuldade que os alunos encontram ao ingressarem no mercado de trabalho é identificar que "ferramenta" usar em determinado momento. Quando eles têm a 
chance de experimentá-las previamente, fica muito mais fácil se tornarem profissionais qualificados e preparados para enfrentar qualquer situação. Aquilo que eles aprendem por si mesmos é superior, em termos educativos e sociais, ao que eles aprendem através da transmissão por outras pessoas.

Os resultados positivos da aplicação da aprendizagem ativa no curso de Engenharia de Produção do Cefet/RJ revelaram a alta receptividade dos alunos ao ensino participativo, contrariando a perspectiva do ensino diretivo tradicional baseado na ampla utilização de aulas expositivas. A opção se mostrou adequada na disciplina Engenharia de Métodos em razão do seu caráter eminentemente aplicado. Assim, foi possível explorar, juntamente com os alunos, os aspectos teórico e prático da disciplina e ao mesmo tempo sensibilizá-los para a importância do desenvolvimento de habilidades, atitudes e valores.

Cabe destacar ainda a facilidade de implementação, uma vez que a dinâmica de grupo realizada não significou alterações na sequência de conteúdos ou na estrutura da disciplina, atuando em caráter complementar às aulas expositivas. Ela apresentou características dos jogos, simulações e da aprendizagem baseada em equipes. O resultado foi a abordagem bem sucedida das dimensões teórica e prática da disciplina, motivando os grupos e as duas turmas. Os alunos trabalharam em pequenos grupos na sala de aula visando alcançar objetivos e metas comuns e se transformar em equipes, além de terem demonstrado domínio dos conteúdos da disciplina e pleno engajamento nas atividades.

O enfoque foi colaborativo no sentido de privilegiar as interações e ainda cooperativo e lúdico, embora a dimensão competitiva dos jogos tenha estado também presente. A estratégia utilizada promoveu uma ruptura com a rotina do trabalho cotidiano em sala de aula e por isso foi muito valorizada pelos alunos. Em que pese o amplo espectro de possibilidades de utilização de estratégias de aprendizagem ativa no ensino de engenharia de produção, elas precisam ser encaradas com mais atenção pelos professores das várias disciplinas. Além de especialmente motivadoras para os alunos, elas favorecem o desenvolvimento de competências em sentido amplo que é, sem dúvida, o requisito por excelência do mercado de trabalho nos dias de hoje. 


\section{REFERÊNCIAS}

BARNES, R. M. Estudo de movimentos e de tempos: projeto e medida do trabalho. São Paulo: Edgard Blücher. 1977.

BAZZO, W. A. Ciência, tecnologia e sociedade e o contexto da educação tecnológica. 3. ed. Florianópolis : UFSC, 2011.

BRUM, K. F.; PURCIDONIO, P. M. Aplicação de uma dinâmica para apoio no ensino de desenvolvimento do método na disciplina de engenharia de métodos. In: ENCONTRO NACIONAL DE ENGENHARIA DE PRODUÇÃO - ENEGEP, 36., 2016. Anais... João Pessoa, PB, Brasil, 2016.

CARMO, B. B. T.; BARROSO, S. H. A.; ALBERTIN, M. R. Aprendizagem discente e estratégia docente: metodologias para maximizar o aprendizado no curso de engenharia de produção. Revista Produção Online, v. 10, n. 4, 2010, p. 779-817,

2010. https://doi.org/10.14488/1676-1901.v10i4.474.

DEPEXE, M. D.; DORNELES, J. B.; COSTA, A. C. F.; SANTOS, D. G. Apresentação de um jogo didático como ferramenta de apoio ao ensino da produção enxuta. In: ENCONTRO NACIONAL DE ENGENHARIA DE PRODUÇÃO - ENEGEP, 26., 2006. Anais... Fortaleza, CE, Brasil, 2006.

DUARTE, N. As pedagogias do "aprender a aprender e algumas ilusões da assim chamada sociedade do conhecimento. Revista Brasileira de Educação, s/v, n. 18, p. 35-40, 2001. http://dx.doi.org/10.1590/S1413-24782001000300004.

FERREIRA, M. L. A.; SOUZA, C. G. O enfoque CTS na disciplina Introdução à Engenharia de Produção do Cefet/RJ. In: ENCONTRO FLUMINENSE DE ENGENHARIA DE PRODUÇÃO - ENFEPRO, 3., 2011. Anais... Rio de Janeiro, RJ, Brasil, 2011.

FERREIRA, M. L. A.; SOUZA, C. G.; CHRISPINO, A. A formação CTS no Cefet/RJ: avaliação do contexto e de uma experiência na graduação em engenharia. In:

CONGRESSO BRASILEIRO DE EDUCAÇÃO EM ENGENHARIA - COBENGE, 42., 2014.

Anais... Juiz de Fora, MG, Brasil, 2014.

FERREIRA, M. L. A.; SILVA, M. B. Aprendizagem ativa e desenvolvimento de competências: experiências e resultados no Cefet/RJ. In: SIMPÓSIO DE EXCELÊNCIA EM GESTÃO E TECNOLOGIA - SEGET, 13., 2016. Anais... Resende, RJ, Brasil, 2016.

FULLMANN, C. O trabalho: mais resultado com menos esforço, custo: passos para a produtividade. São Paulo: Educator, 2009.

GIL, A. C. Métodos e técnicas de pesquisa social. 6. ed. São Paulo : Atlas, 2011.

GRAMIGNA, M. R. Jogos de empresa. 2. ed. São Paulo: Pearson Prentice Hall, 2007.

HUIZINGA, J. Homo ludens: o jogo como elemento da cultura. 4. ed. São Paulo:

Perspectiva, 2000.

IAROZINSKI NETO, A.; LEITE, M. S. A abordagem sistêmica na pesquisa em engenharia de produção. Production, v. 20, n. 1, p. 1-14, 2010. https://doi.org/10.1590/s0103$\underline{65132010005000011 .}$ 
MICHAELSEN, L. K. \& SWEET, M. The essential elements of team-based learning. In: MICHAELSEN, L. K.; SWEET, M. \& PARMELEE, D. X. (Eds.) Team-based learning: small group learning's next big step. Jossey Bass : San Francisco, CA, 2008. p. 7-27. https://doi.org/10.1002/tl.330.

MILITÃO, A. \& MILITÃO, R. S.O.S. dinâmica de grupo. Rio de Janeiro: Qualitymark, 1999.

PARMELEE, D. X. \& MICHAELSEN, L. K. Twelve tips for doing effective Team-Based Learning (TBL). Medical Teacher, v. 32, n. 2, 2010, p. 118-122.

https://doi.org/10.3109/01421590903548562.

PEINADO, J.; GRAEML, A. R. Administração da produção: operações industriais e de serviços. Curitiba: UnicenP, 2007.

POSSEBON, F. R.; FONTANA, J.; BOSS, M. Dinâmica de grupo sobre folha de operações padrão. In: ENCONTRO NACIONAL DE ENGENHARIA DE PRODUÇÃO - ENEGEP, 32., 2012. Anais... Bento Gonçalves, RS, Brasil, 2012.

PRINCE, M. J. Does active learning work? A review of the research. Journal of Engineering Education, v. 93, n. 3, p. 223-231, 2004. https://doi.org/10.1002/j.21689830.2004.tb00809.x

PRINCE, M. J.; FELDER, R. M. Inductive teaching and learning methods: def initions, comparisons, and research bases. Journal of Engineering Education, v. 95, n. 2, p. $123-$ 138, 2006. https://doi.org/10.1002/j.2168-9830.2006.tb00884.x

SILVA, R. R. L.; ZATTAR, I. C.; CLETO, M. G. \& STEFANO, N. M. O uso de jogos e simulação como métodos alternativos de ensino em engenharia no Brasil: uma revisão bibliográfica. Espacios (Caracas), v. 37, n. 5, p. E-3, 2016.

SOLER, R. Jogos cooperativos. 2. ed. Rio de Janeiro : Sprint, 2003.

VIEIRA, R. R. S.; CORREIA, A. M. M.; LUCENA, A. D.; SILVA, A. M. Estudo de tempos e métodos no processo produtivo de uma panificadora localizadas em Mossoró/RN. Revista Eletrônica Gestão \& Sociedade, v. 9, n. 23, p. 977-999, 2015.

http://dx.doi.org/10.21171/ges.v9i23.2029.

ZAMBELO, E. A. O uso de jogos de empresas no ensino superior: um estudo sobre a prática docente. Dissertação (Mestrado) - Programa de Pós-Graduação em Engenharia de Produção da Universidade Estadual Paulista Júlio de Mesquita Filho. Bauru, São Paulo, 2011.

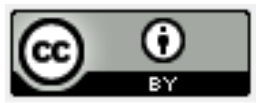

Artigo recebido em 22/02/2017 e aceito para publicação em 18/04/2017

DOI: http://dx.doi.org/10.14488/1676-1901.v17i3.2739 